\title{
Normative, systemic and procedural aspects: a review of indicator-based sustainability assessments in agriculture
}

Conference or Workshop Item

Published Version

Binder, C. R. and Feola, G. (2010) Normative, systemic and procedural aspects: a review of indicator-based sustainability assessments in agriculture. In: 9th European IFSA

Symposium: Building sustainable rural futures, 4-7 Jul 2010, Vienna, Austria, pp. 801-811. Available at

https://centaur.reading.ac.uk/24412/

It is advisable to refer to the publisher's version if you intend to cite from the work. See Guidance on citing.

All outputs in CentAUR are protected by Intellectual Property Rights law, including copyright law. Copyright and IPR is retained by the creators or other copyright holders. Terms and conditions for use of this material are defined in the End User Agreement.

www.reading.ac.uk/centaur 
Central Archive at the University of Reading

Reading's research outputs online 


\title{
Normative, systemic and procedural aspects: a review of indicator-based sustainability assessments in agriculture
}

\author{
Claudia R. Binder ${ }^{a}$ and Giuseppe Feola ${ }^{b}$ \\ anstitute for System Sciences, Innovation and Sustainability Research, University of Graz, Austria, \\ claudia.binder@uni-graz.at \\ ${ }^{b}$ Department of Geography, University of Zurich, Switzerland
}

\begin{abstract}
Several methods for assessing the sustainability of agricultural systems have been developed. These methods do not fully: (i) take into account the multi-functionality of agriculture; (ii) include multidimensionality; (iii) utilize and implement the assessment knowledge; and (iv) identify conflicting goals and trade-offs. This paper reviews seven recently developed multidisciplinary indicator-based assessment methods with respect to their contribution to these shortcomings. All approaches include (1) normative aspects such as goal setting, (2) systemic aspects such as a specification of scale of analysis, (3) a reproducible structure of the approach. The approaches can be categorized into three typologies. The top-down farm assessments focus on field or farm assessment. They have a clear procedure for measuring the indicators and assessing the sustainability of the system, which allows for benchmarking across farms. The degree of participation is low, potentially affecting the implementation of the results negatively. The top-down regional assessment assesses the on-farm and the regional effects. They include some participation to increase acceptance of the results. However, they miss the analysis of potential trade-offs. The bottom-up, integrated participatory or transdisciplinary approaches focus on a regional scale. Stakeholders are included throughout the whole process assuring the acceptance of the results and increasing the probability of implementation of developed measures. As they include the interaction between the indicators in their system representation, they allow for performing a trade-off analysis. The bottom-up, integrated participatory or transdisciplinary approaches seem to better overcome the four shortcomings mentioned above.
\end{abstract}

Keywords: sustainability assessment, indicator, agriculture, sustainability solution space

\section{Introduction}

Sustainability within agricultural systems is widely discussed and is viewed as essential for the transition towards global sustainable development in international fora (UNCED, 1992; OECD, 1999 and 2001; WSSD 2002). Despite wide consensus on its relevance, a high degree of variability can be observed both in how sustainable development in agriculture is defined and how it is practically pursued in the policy-making process. The lack of agreement about the definition has brought some researchers (e.g. Hansen, 1996) to question the usefulness of the concept of "agricultural sustainability".

The variability existing in the policy-making arena is mirrored and supported by the academic debate, where multiple and sometimes contradictory perspectives coexist on how sustainable development in agriculture should be defined and pursued. Consequently, a wide variety of tools and methods have been developed to assess sustainable development in agriculture, which include among others: (i) indicator lists (e.g. Girardin et al., 2000; Rigby et al., 2000; Woodhouse et al., 2000; van der Werf and Petit, 2002) (i) environmental assessment of production alternatives (as in LCA, van der Werf and Petit, 2002), (ii) Indexes or Ecopoints (Taylor et al. 1993; Mayrhofer et al. 1996; van der Werf and Petit, 2002), (iii) linear programming models (Rossing et al., 2007) and (iv) trade-off models of production alternatives, considering economic, ecological and health aspects (Crissman et al., 1998). The majority of methods developed, however, have focused on ecological aspects, and reflect the foci set in sustainable agriculture which is often related to issues such as integrated pest management, organic farming, biodynamic farming, low input agriculture, agro-ecology, low input sustainable agriculture and low external input sustainable agriculture (Rigby and Caceres,1997). 
There are four main shortcomings in sustainability assessment in agriculture:

1. the multi-functionality in agriculture is often not specifically addressed in sustainability assessments (Rossing et al., 2007);

2. there is an imbalance in the modelling and assessment work performed regarding the three dimensions of sustainability, i.e., ecological, economic and social aspects (von Wirén-Lehr, 2001), in favour of the ecological one;

3. research has so far focused on filling important gaps in knowledge and technology, but has omitted to include the step towards utilization and implementation of this knowledge (Rossing et al., 2007); and

4. the assessment results themselves are difficult to implement in decision-making, as conflicting goals and the interaction between indicators has not been sufficiently considered (Morse et al., 2001).

As many different approaches exist, which differ in terms of e.g. goal, methods, and assessment procedure, different performances are expected, with respect of the four above mentioned shortcomings. In this paper we compare seven indicator-based approaches for sustainability assessment in agriculture in terms of the normative, systemic, and procedural dimensions in the assessment procedure (Wiek and Binder, 2005). The analysis and comparison allows for highlighting advantages and disadvantages of the methods and pointing out trade-offs and opportunities for improving the practice of sustainability assessment in agriculture.

\section{Methodological approach}

Figure 1 depicts the assessment process and how the normative, systemic and procedural dimensions are interlinked. In the preparatory phase within the procedural dimension the user group, the involved stakeholders, and their type of involvement (e.g., participatory, transdisciplinary, expert input) are determined. This step, to a large extent, drives the normative and systemic aspects such as the sustainability concept chosen, and system representation. In turn, the normative and systemic dimensions affect the preparatory phase, the selection of the indicators, and the assessment itself.

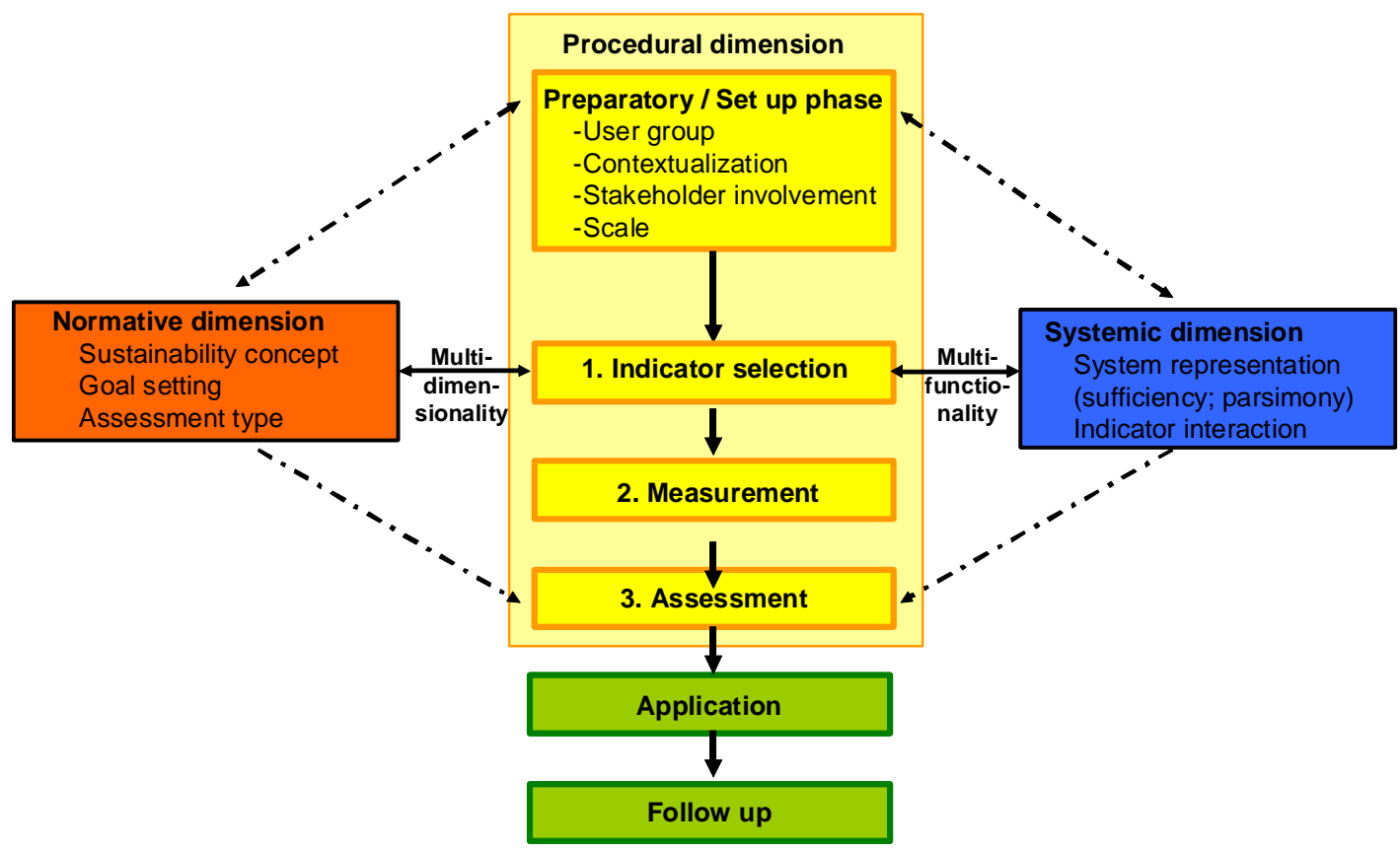

Figure 1. The interrelationship of the normative, systemic and procedural dimensions within the assessment process (after Wiek and Binder, 2005; Binder et al., 2010). 


\section{Normative dimension}

The consideration of the normative dimension is essential if the indicator-based decision-making system is to be useful for assessment and application. Three issues have to be considered: (i) underlying sustainability concept; (ii) goal setting; and (iii) assessment type (Figure 1).

The underlying sustainability concept can be completely theory-based (i.e., Niemeijer 2002; Bossel 1999), or developed in a transdisciplinary procedure, in which for example legislative definitions and stakeholders perspectives can be included (see Wiek and Binder, 2005). It determines to which extent multidimensionality is included in the assessment.

The goals should be derived from the sustainability concept. They operationalize the former and are the basis for the assessment that can take different forms, e.g. the reference to thresholds or ranges. They can be derived by the researchers or in a transdisciplinary process. In either case these goals need to be internally consistent and at the same time allow decision-makers flexibility for taking action (Wiek and Binder, 2005).

Finally, the indicators can be assessed with respect to regulatory standards (e.g., nitrogen in groundwater), targets (Van Cauwenbergh et al., 2007), thresholds (Zahm et al., 2006), and ranges (Wiek and Binder, 2005). Of crucial importance is whether the indicators are aggregated into groups, e.g., social, economic and ecological, and how the groups are weighted.

It should be considered that normative concepts may vary along cultures and parts of the society (Empacher, 2002) and thus, the question to which extent the assessment is applicable to other countries has to be critically studied before extrapolating results or methodologies to other contexts (Binder and Wiek, 2007).

\section{Systemic dimension}

The systemic dimension plays an essential role when selecting and designing the indicators for the assessment. For obtaining an adequate system representation, three issues should be considered; (i) parsimony; (ii) sufficiency; and (iii) indicator interaction.

In general, a system should be represented with as much simplicity as possible (parsimony) and as much complexity as necessary (sufficiency). This implies that, for obtaining an adequate system representation, the most relevant relations among the indicators have to be considered in the analysis (Wiek and Binder, 2005; Binder and Wiek, 2007). The indicators and their relations have to represent the main structures, processes, and functions of the economic, ecological and social fields of the system studied and have to refer to the problems and targets to be tackled and thus are linked to the normative dimension.

\section{Procedural dimension}

We structure the procedural dimension into the procedure itself and stakeholder involvement.

\section{Structure of the procedure}

As mentioned above, the assessment protocol has to be complete, consistent and replicable, if the results should be reproducible, used for benchmarking, to monitor system changes over time, or to evaluate the utility of measures taken. We divide the sustainability assessment process into ideal sub-phases. The sequential presentation may not always correspond to the real implementation, which is characterized by feedback loops and cyclical stages. We defined a preparatory phase and five main steps (Figure 1). In the preparatory or set up phase the basic elements of the assessment are defined, i.e. the system under consideration, the scale of analysis and the user groups of the, the stakeholders to be involved, and the type of their involvement. The core part of the assessment includes three main steps: 
1. First, the selection of the indicators is linked to the normative and systemic aspects mentioned above. It should be based on the specific characteristics of the field, farm or region and the problems existing in the selected system. Important criteria for the selection of indicators should be (Binder and Wiek, 2001; Scholz and Tietje, 2002; Zhen and Routray, 2003; Wiek and Binder, 2005): (i) goal orientation; (ii) system representation; and (iii) data availability. The results of this step include the information on goal specificity of the indicator set (i.e. how well the indicator fits the goals set), its multidimensionality and multifunctionality, and the scale of analysis (Smith and McDonald, 1998; von Wirén-Lehr, 2001; Niemeijer, 2002; Payraudeau and van der Werf, 2005). In this step, the decision is taken of whether or not to include the interaction of indicators and how it will be implemented.

2. Second, the indicator measurement is related to quantification of the indicators and processes. This can be based on statistical data, surveys or qualitative data.

3. Third, in the assessment the normative and systemic aspects are included again (Figure 1). Here one should distinguish between the aggregation and integration of indicators and the specific assessment procedure (Binder et al., 2010).

Then follow the application and in the final follow-up phase the results are reported, management advice developed, and the indicators monitored over time.

\section{Stakeholder involvement}

For an indicator-based sustainability assessment to comprehensively and reliably reflect the salient features of the system, the research and results must be pursued in a society- and policy-conscious framework. We consider participatory and transdisciplinary research methods as essential for doing so (Ravetz, 1999; Thompson Klein et al., 2001; Binder and Wiek, 2007). It has to be noted that in the assessment process as depicted in Figure 1, the decision when and how to involve stakeholders is already taken in the preparatory phase, indicating this to be a key decision in any procedure.

\section{Short overview of the selected approaches}

Seven approaches were selected because they address the three above-mentioned dimensions: (i) the systemic view by providing adequate criteria for system representation, (ii) normative view by including assessment criteria; and (iii) procedural component by providing a structure to the assessment. Most of the approaches selected are recently developed approaches, one of which (SSP) has just recently been applied to the agricultural system Castoldi et al., submitted). One distinction of the selected approaches is the system boundary ranging from focus on farm level to regional scale or across scales (Table 1 ).

The Indicateur de Durabilité des Exploitacions Agricoles (IDEA) analyzes the sustainability at a farm level addressing several premises. A farm must be able to be viable in economic terms, livable for the farmer and his family, and ensure the reproducibility of the environment (Zahm et al., 2006). A total set of 41 indicators is derived accounting for these dimensions.

The Indicator of Sustainable Agricultural Practice (ISAP) focuses on the sustainability of specific agricultural practices. The developed index serves in particular "to compare the reltive hazards to sustainability posed by different farming methods" (Rigby et al., 2001). It allows for an assessment with limited data availability.

The Response-Inducing Sustainability Evaluation (RISE) (Häni et al., 2003 and 2007; Porsche et al., 2004) allows for analyzing and comparing the sustainability of a diversity of agricultural production systems or farms. It balances between the straightforwardness of the analysis, the complexity of the reality, and the transparency of the results making so the output comprehensible for a wider public and applicable by farmers. 
Table 1. Overview of the selected approaches: farm level.

\begin{tabular}{|c|c|c|c|}
\hline Approach & Aim & Target group & Definition of sustainable agriculture \\
\hline IDEA & $\begin{array}{l}\text { To provide an operational tool } \\
\text { for sustainability assessment at } \\
\text { farm level }\end{array}$ & $\begin{array}{l}\text { Planners, policy-makers, } \\
\text { researchers, farmers, } \\
\text { farmer organizations }\end{array}$ & $\begin{array}{l}\text { - Economic viability } \\
\text { - Social livability } \\
\text { - Environmental reproducibility }\end{array}$ \\
\hline ISAP & $\begin{array}{l}\text { To operationalize agricultural } \\
\text { sustainability in order to } \\
\text { support policy making }\end{array}$ & $\begin{array}{l}\text { Researcher and policy } \\
\text { makers }\end{array}$ & $\begin{array}{l}\text { - Minimization of off-farm inputs } \\
\text { - Minimization of non-renewable resources } \\
\text { - Maximization of natural biological } \\
\text { processes } \\
\text { - Promoting local biodiversity } \\
\text { - Enhancing farmers' life quality } \\
\text { - Increasing farmers' self reliance } \\
\text { - Sustaining farms' profitability } \\
\text { - Improving equity } \\
\text { - Meeting society's needs for food and } \\
\text { fibre }\end{array}$ \\
\hline RISE & $\begin{array}{l}\text { To provide a simple and cheap } \\
\text { but holistic tool to: } 1 \text { ) evaluate } \\
\text { the degree of sustainability at } \\
\text { farm level; } 2 \text { ) visualize } \\
\text { potentials and failures, thus } \\
\text { inducing management } \\
\text { responses }\end{array}$ & Farmers & $\begin{array}{l}\text { - Productivity } \\
\text { - Competitiveness } \\
\text { - Efficiency } \\
\text { - Protection and improvement of the } \\
\text { natural environment and socio- } \\
\text { economic conditions of local } \\
\text { communities }\end{array}$ \\
\hline
\end{tabular}

The Framework for the Evaluation of Sustainable Land Management (FESLM) (Smyth and Dumanski, 1993) provides a strategic framework approach for evaluating sustainable land management. It departs from the premise that sustainability is not rigid, but has to be capable to capture changes in typologies of areas and development over time. The framework "offers the possibility of providing preliminary estimates' of acceptable reliability, without waiting for all of the final data." (Smyth and Dumanski, 1993).

Table 2: Overview of the selected approaches: regional level or across scales.

\begin{tabular}{|c|c|c|c|}
\hline Approach & Aim & Target group & Definition of sustainable agriculture \\
\hline FESLM & $\begin{array}{l}\text { To guide analysis of land use } \\
\text { sustainability, through a series of } \\
\text { scientifically sound, logical steps. It is: } \\
\text { integrative (considers all interacting } \\
\text { factors), concerned with evaluation, } \\
\text { systematic }\end{array}$ & Planners & $\begin{array}{l}\text { - Productivity } \\
\text { - Security } \\
\text { - Protection } \\
\text { - Viability } \\
\text { - Acceptability }\end{array}$ \\
\hline MMF & $\begin{array}{l}\text { To assess multiscale sustainability with } \\
\text { emphasis on peasant agriculture and } \\
\text { natural resource management. }\end{array}$ & $\begin{array}{l}\text { Researcher and policy } \\
\text { makers }\end{array}$ & $\begin{array}{l}\text { - Productivity } \\
\text { - Stability } \\
\text { - Resilience } \\
\text { - Reliability } \\
\text { - Adaptability }\end{array}$ \\
\hline SAFE & $\begin{array}{l}\text { To identify, develop and evaluate } \\
\text { agricultural production systems, } \\
\text { techniques and policies }\end{array}$ & $\begin{array}{l}\text { Researcher and policy } \\
\text { makers }\end{array}$ & $\begin{array}{l}\text { - Biological diversity } \\
\text { - Productivity } \\
\text { - Regeneration } \\
\text { - Capacity } \\
\text { - Vitality } \\
\text { - Ability to function } \\
\end{array}$ \\
\hline SSP & $\begin{array}{l}\text { To identify the sustainability solution } \\
\text { space in which stakeholders can find } \\
\text { solutions and the system remains or } \\
\text { becomes more sustainable }\end{array}$ & $\begin{array}{l}\text { All stakeholders affecting } \\
\text { systems' sustainability } \\
\text { planners, farmers, policy } \\
\text { makers }\end{array}$ & $\begin{array}{l}\text { - Theory based combined with a } \\
\text { transdisciplinary process. } \\
\text { Includes: multidimensionality } \\
\text { and multi-functionality }\end{array}$ \\
\hline
\end{tabular}

The Multiscale Methodological Framework (MMF) (Lopez-Ridaura, 2002, 2005) aims at assessing sustainability at multiscale level with emphasis on peasant agriculture and natural resources management. It is based on a discipline independent systems approach and aims at "building a multi- 
stakeholder and object driven platform in which objectives and constraints of the stakeholders are coupled to the attributes in order to arrive at useful sets of criteria and specific indicators, meaningful to the stakeholders at different scales." (Lopez-Ridaura et al., 2005).

The Sustainability Assessment of the Farming and the Environment (SAFE) (Van Cauwenbergh, 2007) proposes a holistic, hierarchical methodology for assessing the sustainability of the agro-ecological system. SAFE analyzes the effect of farm activities at plot, farm and regional level.

The Sustainability Solution Space for Decision Making (SSP) (Wiek and Binder, 2005; Binder and Wiek, 2007; Castoldi et al., 2007; Binder et al., 2008; Binder et al., 2010) is a systemic, multidisciplinary and, as far as possible, a dynamic approach, thanks to the analysis of the links between the indicators used. The method uses indicators' targets in the form of ranges. "A sustainability range of an indicator is the largest range within which a sustainable development can take place" (Wiek and Binder, 2005). The result is the largest Sustainability Solution Space possible, which is determined through the examination of consistencies and contrasts between the ranges and through the ranking and composition of targets.

\section{Results and discussion}

The analysis of the normative, systemic and procedural characteristics of the selected approached allowed for identifying similarities and differences among the methods. We group the methods in three types: top-down farm assessment, top-down regional assessment, bottom-up integrated participatory or transdisciplinary assessment. In the following the typology of the approaches is presented and the advantages and disadvantages for each group are discussed.

Figure 2 illustrates the focus of each method with respect to the normative, systemic and procedural dimension discussed. The methods can be structured in three typologies as follows:

1. Top-down, farm assessment (RISE, IDEA, ISAP). This group relates to the methods which focus on assessing a farm or a field. The user group is usually the farmer himself or industry working with farmers groups, and no participation occurs. Consequently, the indicators are derived top down and the way on how they have to be measured and calculated is determined by a clearly structured methodological procedure. Some of these methods tend to focus on ecological aspects or try to include to some extent also the economic and social perspectives of sustainability but do not consider the multi-functionality of agriculture. Finally, indicators interaction is not taken into account, even though composed indicators are built, for example in RISE (Häni et al., 2003 and 2007). The results from these methods can relatively easily be discussed with farmers and the procedure allows for monitoring and to some extent benchmarking across regions.

2. Top-down, regional assessment with some stakeholder participation (FESLM, SAFE). This group relates to methods which study the regional scale or are applicable to the farm as well as the regional level. They include stakeholder participation in the indicator development and have usually multiple stakeholders who are likely to use the results. They always include the ecologic, economic and social dimension of sustainability. However, they do not consider the interrelationship among the indicators, impeding the analysis of trade-offs when designing measures. FESLM translates global concerns to the farm level, whereas SAFE claims to be applicable by both farmers and decision-makers.

3. Bottom-up, integrated participatory or transdisciplinary approach (MMF, SSP). This group refers to methods which ideally focus at the regional scale with multiple stakeholders as user group. They include stakeholder participation throughout the process, including the goal setting process and complement it with theoretical scientific knowledge (SSP). The system is represented including the interrelationship among the indicators and the assessment relies on a combination of quantitative (e.g. linear programming) and qualitative (e.g. workshops, expert interviews) tools. The bottom up process and the large extent of stakeholder involvement supports the likeliness that the results will be applied and make the assessment 
tool flexible for different contexts, yet, it makes a monitoring and benchmarking across regions extremely difficult.

Concerning multidimensionality, which refers to the normative dimension, the three typologies perform uniformly. That is, the assessment is based on a multidimensional definition of sustainability. Furthermore, it is also uniformly acknowledged that indicators referring to the three dimensions have to be measured separately and not aggregated in a single index. Therefore, the reviewed methods overcome the shortcoming represented by the imbalance of the three sustainability dimensions observed by von Wirén-Lehr (2001) in the practice of sustainability assessment in agriculture.

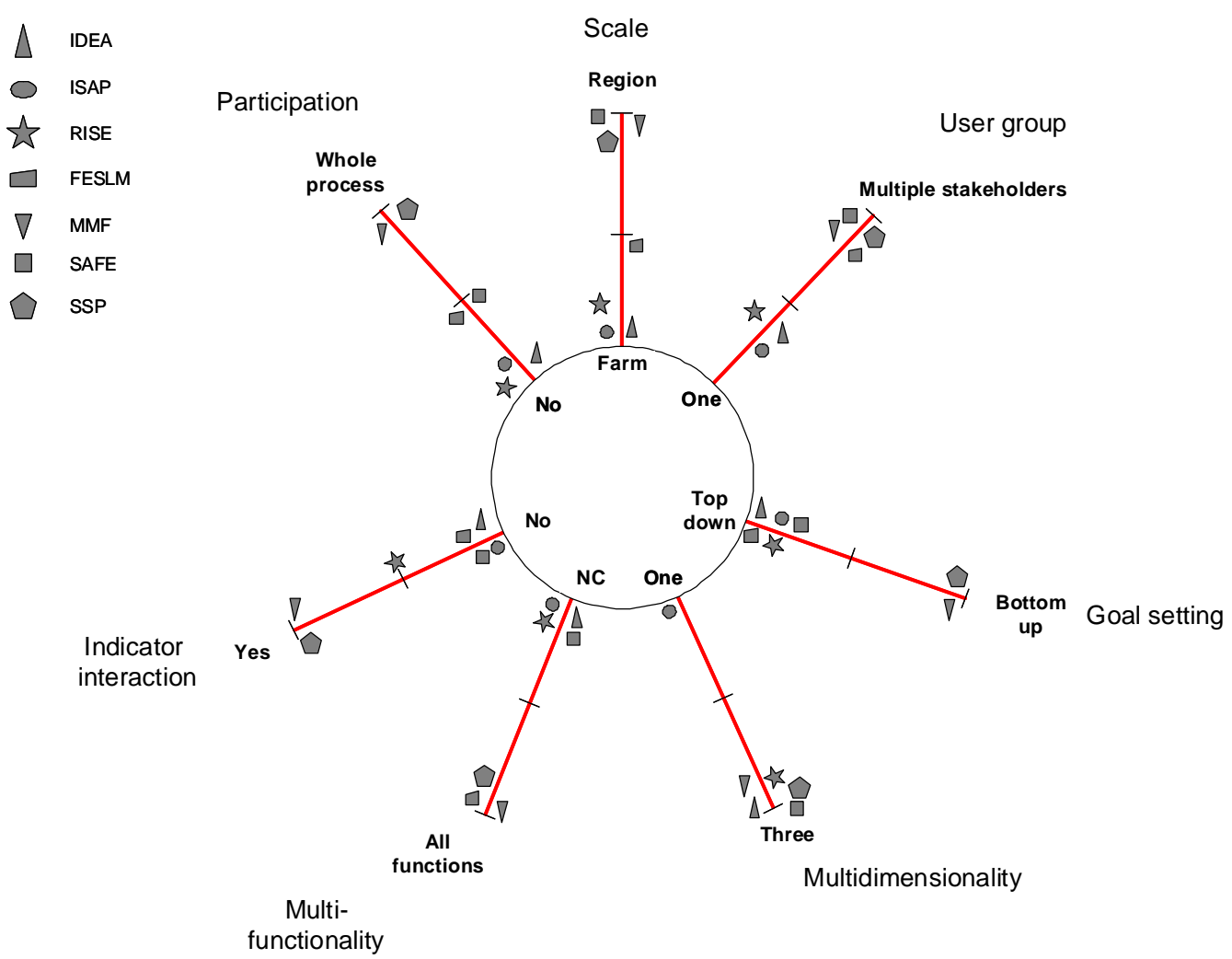

Figure 2. Comparison of the seven approaches with respect to the principal indicator of the normative, systemic and procedural dimension (Binder et al., 2010).

Concerning indicators interaction and multi-functionality, both referring to the systemic dimension, a significant difference is observed between the top-down (typologies 1 and 2) and the bottom-up (typology 3) approaches. In effect, the methods grouped in the typologies 1 and 2 do not consider either multi-functionality or the interactions among indicators. This represents a disadvantage, because these assessment methods may not achieve an adequate system representation. On the other hand, typology 3 considers both multi-functionality and interactions. In this respect, it can be argued that these approaches are able to render a more complex and complete picture of the system's functioning. This is achieved by approaching the procedural dimension in a different way, i.e. (i) by involving different stakeholders, and especially expert and laymen, (ii) by adapting the indicators' list to the characteristics of each specific system, and (iii) by integrating ad-hoc developed quantitative (e.g. trade-off analysis, linear programming) with qualitative (e.g. workshops, scenario building and analysis) assessment tools. Stakeholder participation, which in typology 3 is combined with a high adaptability to the specific context under assessment, is likely to enhance the applicability of the results (Ravetz, 1999; Binder and Wiek, 2007), thus supporting to meet the need 
expressed by Rossing et al. (2007) of bridging knowledge and implementation of the knowledge. Interestingly, the applicability in one system is achieved at the expenses of the reproducibility and benchmarking of the results among different systems, as the assessment (i.e. indicators selection, assessment goals and criteria), is extremely tailored to the specific system under assessment. Furthermore, due to the participation of different stakeholders, the need to select the indicators and to define the scale of analysis and the border of the system, the assessment procedure may tend to be time- and resources-consuming, which represents an obvious disadvantage. Such a characterization in terms of applicability of the methods grouped in typology 3 is significantly different to that of methods grouped in typology 1 . The latter are characterized by a relatively "easy" procedure, which is highly standardized and reproducible (e.g. pre-selected indicators, system definition and scale of analysis), which also allows for benchmarking and comparison among different systems. However, the absence of stakeholder participation and the low adaptability of the assessment procedure and tools to the specific system are likely to reduce the applicability of the assessment results.

The methods grouped in typology 2 show similarities, in terms of applicability, with both typologies 1 and 3. For example, stakeholder participation is considered an option, but is not structurally integrated in the assessment procedure. Similarly, indications concerning the indicators to be used exist, but there is no pre-defined selection to be adopted as standard in different contexts. Because this typology is characterized by leaving a significant room for the researcher in orienting the assessment's procedure, it may show a mixture of the advantages and disadvantages, which distinguish typologies 1 and 3.

In summary, all the typologies are characterized by strength and weaknesses. However, from an overall perspective, the methods grouped in the typology 3 seem to better overcome the four shortcomings of sustainability assessment in agriculture mentioned above. They are multidimensional, multifunctional, and explicitly consider interactions among the indicators. Furthermore, they strongly address the applicability of the results, by involving the stakeholders in the assessment procedure and providing them scenarios (MMF) or a space for decision-making (SSP) which can support them in sustainably developing their system.

\section{Conclusions}

This paper provided a review of seven indicators-based assessment approaches for agriculture. These approaches were analyzed with respect to three dimensions: a normative a systemic and a procedural one. Such an analysis shows how these approaches only partially fulfill the current needs on agricultural sustainability assessment, namely (i) multi-functionality of agriculture; (ii) multidimensionality (balance between ecological, economic and social aspects); (iii) create base for making a step towards utilization and implementation of the assessment knowledge; and (iv) identify conflicting goals and trade-offs by including the interaction between indicators. The review highlighted the advantages and disadvantages in the way the steps of the assessment are pursued, i.e. goal setting, choice of assessment type, indicators' selection and aggregation or integration, structure of the procedure, and stakeholders' involvement. In doing so three types of indicator based assessments were identified: (i) top-down, farm assessment; (ii) top-down, regional assessment with some stakeholder participation; (iii) bottom-up, regional approaches with participation throughout the assessment process; and (iv) transdisciplinary integrated assessment. Each of these assessment types has specific advantages and disadvantages. If, however, the four above mentioned shortcomings are to be overcome, the authors recommend to performing a transdisciplinary integrated assessment. The method proposed for doing so is the Sustainability Solution Space SSP, The approach allows for obtaining a sustainability solution space within which stakeholders and policymakers can take their decisions, knowing that they are still within a sustainable path. The space is constructed by utilizing on the interaction between indicators, which furthermore provides the basis for a trade-off analysis when assessing strategies for improving the sustainability of the system. 
Finally, stakeholder involvement occurs in different phases, allowing for ownership of the results and a higher probability of their implementation.

\section{References}

Binder, C. and A. Wiek (2001) Sustainability spaces: a new concept to evaluate development using indicator systems. Inaugural Conference for Industrial Ecology, Netherlands, November 12-14.

Binder, C.R. and A. Wiek (2007) The role of transdisciplinary processes in sustainability assessment of agricultural systems. In: Häni et al. F.J., Pintér L., Herren H.R. (eds), From Common Principles to Common Practice. Proceedings and Outputs of the first Symposium of the International Forum on Assessing Sustainability in Agriculture (INFASA). International Institute of Sustainable Development and Swiss College of Agriculture, Bern, pp. 33-48.

Binder ,C.R., Feola, G. and J. Steinberger (2010) Considering the normative, systemic and procedural dimensions in indicator-based sustainability assessments in agriculture, Environmental Impact Assessment Review 30:71-81.

Binder, C.R., Steinberger, J., Brundiers, K., Schmidt, H. and A. Schmid (2008) Nachhaltigkeit in der Schweizerischen Milchwertschöpfungskette. Schlussbericht, Soziale und Industrielle Ökologie, Geographisches Institut. Universität Zürich. Zürich, 35p.

Bossel, H. 1999. Indicators for Sustainable Development: Theory, Methods, Applications. International Institute for Sustainable Development, Winnipeg.

Castoldi, N.B.L., Steinberger, J. and C.R. Binder (2007) Sustainability solution space using agro-ecological indicators at field level. In: M. Donatelli, e.a. (editor), Farming Systems Design 2007, Int. Symposium on Methodologies on Integrated Analysis on Farm Production Systems, Catania, pp. 99-100.

Crissman, C.C., Antle, J.M. and S. Capalbo (eds) (1998) Economic, Environmental and Health Tradeoffs in Agriculture: Pesticides and the Sustainability of Andean Potato Production. Kluwer Academic Publisher, Dordrecht.

Empacher, C. (2002) Soziale Dimensionen der Nachhaltigkeit. Perspektiven der Konkretisierung und Operationalisierung. ISOE, Frankfurt.

Girardin, P., Bockstaller, C. and H. Van der Werf (2000) Assessment of potential impacts of agricultural practices on the Environment: the AGRO*ECO method. Environmental Impact Assessment Review 20, 227-239.

Häni, F., Braga, F., Stämpfli, A., Keller, T., Fischer, M. and H. Porsche (2003) RISE, a Tool for Holistic Sustainability Assessment at the Farm Level. International Food and Agribusiness Management Review 6, 78-90.

Häni, F., Gerber, T. F., Stämpfli, A., Porsche, H., Thalmann, C. and C. Studer (2007) RISE: A Tool for Improving Sustainability in Agriculture. A case study with tea farmers in southern India. In: Häni F.J., Pintér L., Herren H.R. (editors), From Common Principles to Common Practice. Proceedings and Outputs of the first Symposium of the International Forum on Assessing Sustainability in Agriculture (INFASA). International Institute of Sustainable Development and Swiss College of Agriculture, Bern, pp. 121-148.

Hansen, J.W. (1996) Is Agricultural Sustainability a Useful Concept? Agricultural Systems 50, 117-143.

Lopez-Ridaura, S. (2005) Multiscale Methodological Framework to derive criteria and indicators for sustainability evaluation of peasant natural resource management system. Environment, Development and Sustainability 7, 51-69.

Mayrhofer, P., Steiner, C., Gärber, E. and E. Gruber (1996) Regionalprogramm Ökopunkte Niederösterreich. Informationsheft. NÖ Landschaftsfonds, Wien, Austria.

Morse, S., McNamara, N., Acholo, M. and B. Okwoli (2001) Sustainability indicators: the problem of integration. Sustainable Development 9, 1- 15.

OECD (Organization for Economic Cooperation and Development) (2001) Environmental Indicators for Agriculture. Methods and Results. OECD Publication Service, Paris. 
Niemeijer, D. (2002) Developing indicators for environmental policy: data driven and theory-driven approaches examined by example. Environmental Science and Policy 5, 91-103.

Payraudeau and van der Werf, S. and H.M.G. van der Werf (2005) Environmental impact assessment for a farming region: a review of methods. Agriculture Ecosystems \& Environment 107, 1-19.

Porsche et al. H., Fischer, M., Braga, F. and F. Häni et al. (2004) Introduction of the Sustainability Assessment Tool RISE into Canadian Agriculture. Working paper.

Ravetz, J. (1999) Citizen participation for integrated assessment: new pathways in complex systems. International Journal of Environment and Pollution 11, $331-50$.

Rigby, D. and D. Caceres (1997) The Sustainability of Agricultural Systems. Working Paper No. 10, Institute for Development Policy and Management, University of Manchester.

Rigby, D., Howlett, D. and P. Woodhouse (2000) A Review of Agricultural and Rural Livelihood Sustainability. Working Paper No.1, Department for International Development Research Project No. R7076CA.

Rigby, D., Woodhouse, P., Young, T. and M. Burton (2001) Constructing a farm level indicator of sustainable agricultural practice. Ecological Economics 39, 463-478.

Rossing, W.A.H., Zander, P., Josien, E., Groot, J.C.J., Meyer, B.C. and A. Knierim (2007) Integrative modeling approaches for analysis of impact of multifunctional agriculture: A review for France, Germany and the Netherlands. Agriculture, Ecosystem and Environment 120, 41-57.

Scholz, R.W. and O. Tietje (2002) Embedded case study methods. Integrating quantitative and qualitative knowledge. Sage, Thousand Oaks, London.

Smith, C.S. and G.T. McDonald (1998) Assessing the sustainability of agriculture at the planning stage. Journal of Environmental Management 52, 15-37.

Smyth, A.J. and J. Dumanski (1993) FESLM: An international framework for evaluating sustainable land management. Food and Agriculture Organization of the United Nations (FAO).

Taylor, D.C., Mohamed, Z.A., Shamsudin, M.N., Mohayidin, M.G. and E.F.C. Chiew (1993) Creating a farmer sustainability index: a Malaysian case study. Am. J. Alter. Agric. 8, 175-184.

Thompson Klein, J., Grossenbacher-Mansuy, W., Häberli, R., Bill, A., Scholz, R.W. and M. Welti (editors) (2001) Transdisciplinarity: Joint Problem Solving Among Science, Technology and Society: An Effective Way for Managing Complexity. Birkhäuser, Basel.

UNCED (United Nation Conference on Environment and Development) (1992) Agenda 21 - an action plan for the next century. Endorsed at the United Nations Conference on Environment and Development, New York.

Van Cauwenbergh, N., Biala, K., Bielders, C., Brouckaert, V., Franchois, L., Garcia Cidad, V., Hermy, M., Mathijs, E., Muys, B., Reijnders, J., Sauvenier, X., Valckx, J., Vanclooster, J., Van der veken, B., Wauters, E. and A. Peeters (2007) SAFE - a hierarchical framework for assessing the sustainability of agricultural systems. Agriculture, Ecosystem and Environment 120, 229-242.

Van der Werf, H.M.G. and J. Petit (2002) Evaluation of the environmental impact of agriculture at the farm level: a comparison and analysis of 12 indicator-based methods, Agriculture Ecosystem and Environment 93, 131-145.

Von Wirén-Lehr, S. (2001) Sustainability in agriculture-an evaluation of principal goal-oriented concepts to close the gap between theory and practice. Agriculture Ecosystems and Environment 84, 115-129.

Wiek, A. and C. Binder (2005) Solution spaces for decision-making - a sustainability assessment tool for cityregions. Environmental Impact Assessment Review 25, 589-608.

Woodhouse, P., Howlett, D. and D. Rigby (2000) A Framework for Research on sustainability Indicators for Agriculture and Rural Livelihoods. Working Paper No.2, Department for International Development Research Project No. R7076CA.

WSSD (World Summit on Sustainable Development) (2002) Report of the World Summit on Sustainable Development. Johannesburg.

Zahm, F., Viaux, P., Girardin, P., Vilain, L. and C. Mouchet (2006) Farm Sustainability Assessment using the IDEA Method: From the concept of farm sustainability to the case studies on French farms. In: Häni et al. F.J., 
Pintér L., Herren H.R. (editors), From Common Principles to Common Practice. Proceedings and Outputs of the first Symposium of the International Forum on Assessing Sustainability in Agriculture (INFASA). International Institute of Sustainable Development and Swiss College of Agriculture, Bern, pp. 77-110.

Zhen, L. and J.L. Routray (2003) Operational Indicators for Measuring Agricultural Sustainability in Developing Countries. Environmental Management 32, 34-46. 